\title{
Cost-effectiveness of home non-invasive ventilation in COPD group GOLD D patients
}

\author{
BERES Enikö ${ }^{1}$, BABES Katalin', BERES Zsolt-Levente ${ }^{2}$, DAINA Lucia Georgeta ${ }^{3}$, \\ DAINA Cristian Marius ${ }^{3}$, CHEREGI Cornel ${ }^{4}$, CIUMARNEAN Lorena ${ }^{5}$, DOGARU Gabriela ${ }^{6}$
}

Editor: Constantin Munteanu, Romanian Association of Balneology,office@bioclima.ro

Reviewers: Silisteanu Sinziana Calina and Rotariu Mariana

*Corresponding authors: DAINA Cristian Marius, E-mail: cristi daina@yahoo.co.uk

1. Cardiology Department, University of Oradea, Faculty of Medicine and Pharmacy, Romania

2. Clinical County Emergency Hospital Oradea, Romania

3. Psycho-neurosciences and Recovery Department, University of Oradea, Faculty of Medicine and Pharmacy, Romania

4. Surgery Department, University of Oradea, Faculty of Medicine and Pharmacy, Romania

5. Internal Medicine Department, University of Medicine and Pharmacy „Iuliu Hatieganu”Cluj Napoca, Romania

6. Medical Rehabilitation Department, University of Medicine and Pharmacy „Iuliu Hatieganu”Cluj Napoca, Romania

\section{Abstract}

Introduction. Chronic obstructive pulmonary disease (COPD) is a major cause of morbidity and mortality, estimated to be the third most common cause of death by 2020 . The natural evolution of the disease is characterized by frequent exacerbations, severe exacerbations evolving with respiratory acidosis. Introducing home non-invasive ventilation (NIV) in the management of COPD group GOLD (Global Initiative for Chronic Obstructive Lung Disease) D patients generates supplementary costs, but the decreasing of the number of severe exacerbations will decrease the costs of drug treatment and hospitalization. This balance can be verified through a careful study of cost-effectiveness through modern methods of assessing the costs and years of life gained in relation to quality of life.

Material and method. This prospective study took place in the Emergency Department of the Bihor County Clinical Emergency Hospital, Oradea, between 01 October 2017 - 31 October2018, with a follow-up period of 2 years. We included 36 Group risk D COPD patients, presented with severe exacerbation that required NIV; the patients were divided into two study groups according to the treatment scheme after discharge (standard medication according to GOLD guidelines and long-term oxygen therapy - LTOT vs. LTOT + NIV). We follow-up at 2 years with the study group, and analyze the following: number of exacerbations (moderate and severe), number of hospitalizations, mortality rate in two years, average costs for the treatment of exacerbations and for stable COPD periods, quality adjusted life year (QALY).

Results and discussions. From 36 enrolled, 10 patients benefited from home NIV. The number of exacerbations was significantly lower in the NIV group compared with the LTOT group $(1.72 \pm 0.79$ vs $3.54 \pm 1.18)$. The incremental costeffectiveness ratio (ICER) showed a net gain of $31 \%$ from gross product (GDP) per capita (5,641.71 $\pm 1,737.0$-euro vs 9,272.3 \pm 3,681.9 euro) per quality adjusted life year (QALY) for each patient.

Conclusions. Introduction home-NIV demonstrated clinical improvement and higher cost-effectiveness over LTOT alone in Class Risk D, COPD patients after discharge following a severe exacerbation.

Keywords: chronic obstructive pulmonary disease, non-invasive ventilation, cost-effectiveness, quality adjusted life year,

\section{INTRODUCTION}

Chronic obstructive pulmonary disease (COPD) remains one of the leading global causes of mortality and morbidity $(1,2,3,4)$, estimated to be the third most common cause of death by $2020(3,5)$. The natural evolution of the disease is characterized by frequent exacerbations $(2,4)$, decreased quality of life, especially in COPD risk class $\mathrm{C}$ and $\mathrm{D}$, and increased economic costs $(3,4)$.

Severe COPD exacerbations are associated with respiratory acidosis and hypercapnia, usually determined hospital admission and need for ventilatory support $(7,8,9,21)$. Although non-invasive ventilation (NIV) proved his efficiency in COPD patients with acute respiratory failure, persistent hypercapnia after discharge is associated with increased mortality rate and early readmission (3). Before 2013 the readmission rate was $20 \%$ (4), and in some countries (USA and UK for example) hospitals are penalized for readmissions under 28 days. These factors contributed to the increased interest in development of new therapies to prevent relapse in these patients $(5,6)$. The hospital, through the management system created (rules, principles, decisionmaking procedures) has the primary objective of providing quality, efficient and high-performance medical services $(7,8)$.

One of these relatively new treatment options is homeNIV added to the long-term oxygen therapy (LTOT), in COPD Group D patients with chronic hypercapnia $(12,16)$. Clinical efficiency of home-NIV raised controversies between researchers because some of the clinical studies didn't show any improvement in hypercapnia level or on mortality. However, the question remains if in these studies NIV wasn't or not applied in an optimized manner, selection of patients was correct or 
not (13). Recently, European Respiratory Society Task Force (ERSTF) reviewed and published in 2019 evidence-based recommendations for the clinical application of LTH-NIV in chronic hypercapnic COPD patients (14).

Introducing home- NIV in the treatment scheme of COPD patients generates supplementary charges, but clinical improvement with reducing number of exacerbations leads to decreased hospitalization costs and pharmaceutical treatment expenditures $(17,18)$. This balance can be verified only through a careful study of cost-effectiveness with modern methods including cost assessment and gained quality adjusted life years (QALY) $(19,20)$. These studies are specific for every country, health systems varying in characteristics and individual costs $(22,23)$. The aim of our study was to evaluate the clinical and economic impact of NIV supplementation to LTOT compared to standard therapy with LTOT in COPD group D patients with severe hospitalized exacerbation.

\section{Material and method}

\subsection{Study selection}

This prospective, observational study took place in the Emergency Department of the Bihor County Clinical Emergency Hospital, Oradea, between 01 October 2017 31 October2018, with a follow-up period of 2 years. The inclusion criteria were: patients with a documented diagnosis of COPD, Class risk $\mathrm{D}$, aged $\geq 40$ years, hypercapnia $>55 \mathrm{mmHg}$ and respiratory acidosis witch required NIV. The exclusion criteria were: pregnancy, any oncologic diagnosis in the last 5 years, younger than 40 years, unable to sign informed consent. The study was conducted in accordance with the Declaration of Helsinki, and the protocol was approved by the Ethics Committee of County Clinical Emergency Hospital, Oradea.

\subsection{Objectives}

The main objectives of the study were: the number of exacerbations (moderate and severe), readmission rate and general mortality rate in the observation period (24 months). Secondary objectives were economic data, QALY, ratio between costs/QALY.The difference in costs / QALY ratio was compared to the gross domestic product (GDP) per capita to demonstrate the economic importance of the gain or loss through this intervention in the treatment scheme of Class risk D COPD patients.

\subsection{Data collection}

Data were collected from the patient's medical record obtained after evaluation in the Emergency Department, and a number was allocated after study inclusion. The following data were collected: age, gender, location of residency (urban or rural), cigarette-smoking history, arterial blood gas parameters (Pco22( $\mathrm{mmHg})$, ph, Po2 $(\mathrm{mmHg}))$, number of moderate and severe exacerbations (defined by the GOLD 2017), mortality rate. The study population was divided by the treatment scheme in two samples (LTOT or LTOT+NIV). This division was undertaken in order to facilitate a comparison of the clinical factors as well as the economic factors.

Patient follow-up was realized by phone combined with verification of electronic registers of all hospitals in Bihor County with respiratory ward. The compliance with the NIV was checked up with the company who lease the NIV device (from the digital register of each device).

The follow-up criteria were the following: treatment scheme: LTOT or LTOT+NIV; daily usage of LTOT and NIV (h/day); number of recurrences in follow-up period (moderate and severe); number of hospital admission for exacerbation; all-cause mortality.

According to the collected data non-compliant patients (oxygen usage under $18 \mathrm{~h} /$ day and NIV usage under $6 \mathrm{~h} /$ day) and those who changed the treatment regimen during the follow-up period (LTOT to LTOT+NIV or inversely) were excluded.

\subsection{Economic study}

The best economic indicator for a medical intervention is the incremental cost-effectiveness ratio (ICER) or cost / effect difference.

In our case the effect was represented by the Quality Adjusted Life Years (QALY), and the costs were calculated adding the next amounts (standard prices according to the National Health Assurance's expenses list):

costs of baseline treatment (bronchodilators and respiratory anti-inflammatory drugs) - approximately 63 euro / month;

costs of treatment for moderate exacerbation (without admission): medical consult 6 euro + medication (antibiotics, oral anti-inflammatory and mucolytic drugs) approximately 31 euro $=37$ euro / exacerbation;

costs of treatment for severe exacerbation (with admission): amount charged per case $=$ standard amount per case $\mathrm{x}$ severity index $=323$ euro x $2.6337=850$ euro / exacerbation (27);

expenses of LTOT: 40 euro / month;

expenses of domiciliary NIV: 120 euro / month.

Approximation of QALY was made based on utility values taken from BLISS study average life quality scores (26):

stabile COPD patient's utility score: 0.6014 , during moderate recurrence: 0.5112 ( 1 month),

In case of severe exacerbation, the first month is noted with 0.2556 and 0.4511 for the next 2 months.

\subsection{Statistical analysis}

The data were collected in 2016 Microsoft Excel software (version 18.2006.1031.0, Microsoft, Redmond, Washington, DC, USA), and transferred to SPSS 
software (IBM SPSS Statistics 25.0.0.0, Armonk, New York, NY, USA) for the statistical analysis. The quantitative variables were expressed by their average \pm standard deviation (SD), respectively median and interquartile range in case of skewed distribution; and number of observations with percentage in case of categorical variables. The type of distribution for continuous variables was determined using the Kolmogorov-Smirnov test. Statistical significance was set at $p<0.05$. The comparison of the study groups was realized with Student t-test, respectively Mann-Whitney (in case of skewed distribution) and chi-square test with Yates' correction for categorical variables.

ICER was calculated using the usual formula: C1C0/E1-E0. $\mathrm{C} 1=$ total cost of care for patients from LTOT+NIV group. C0 = total cost of care for patients from LTOT group; E1 = QALY for LTOT+NIV group. $\mathrm{E} 0=\mathrm{QALY}$ for LTOT group.

\section{Results}

The study included 53 patients with COPD Class risk D presented with respiratory acidosis required NIV. 5 patients were excluded due to non-compliance to the treatment (3 non-compliance to NIV and 2 noncompliance to LTOT) and 2 due to transition between groups (both from LTOT group to LTOT+NIV group). From the remaining 46 patients only 36 could be contacted by phone to confirm the number of recurrences in the follow-up period. 10 patients benefited from domiciliary NIV. The baseline characteristics of the 2 study groups are presented in Table 1 .

Table 1. Baseline characteristics of the study groups

\begin{tabular}{|l|l|l|l|}
\hline $\begin{array}{l}\text { Demographic } \\
\text { characteristics }\end{array}$ & $\begin{array}{l}\text { LTOT + } \\
\text { NIV group } \\
\text { (n=10) }\end{array}$ & $\begin{array}{l}\text { LTOT } \\
\text { group } \\
\text { (n=26) }\end{array}$ & $\begin{array}{l}\text { Statistical } \\
\text { significance } \\
(\mathbf{p})\end{array}$ \\
\hline Gender (Male/Female) & $4 / 6$ & $13 / 13$ & 0.8684 \\
\hline $\begin{array}{l}\text { Age (years) - average } \pm \\
\text { SD }\end{array}$ & $68.5 \pm 9.5$ & $69.8 \pm 10.7$ & 0.7364 \\
\hline $\begin{array}{l}\text { Provenience } \\
\text { (Urban/Rural) }\end{array}$ & $3 / 7$ & $11 / 15$ & 0.7666 \\
\hline $\begin{array}{l}\text { Follow-up period } \\
\text { (months) - average } \pm \text { SD }\end{array}$ & $17.2 \pm 3.1$ & $17.1 \pm 3.5$ & 0.9231 \\
\hline $\begin{array}{l}\text { LTOT = long time oxygen therapy; NIV } \\
\text { standard deviation }\end{array}$ & & \multicolumn{3}{|l|}{-invasive ventilation; SD $=$} \\
\hline
\end{tabular}

\subsection{Clinical results}

The evolution of clinical criteria for the 2 groups is presented in the next table (Table no. 2).

Table 2. Evolution of clinical criteria for the study groups

\begin{tabular}{|l|l|l|l|}
\hline Clinical characteristics & $\begin{array}{l}\text { LTOT }+ \\
\text { NIV group } \\
(\mathbf{n = 1 0 )}\end{array}$ & $\begin{array}{l}\text { LTOT } \\
\text { group } \\
(\mathbf{n = 2 6})\end{array}$ & $\begin{array}{l}\text { Statistical } \\
\text { significance } \\
(\mathbf{p})\end{array}$ \\
\hline $\begin{array}{l}\text { Number of moderate } \\
\text { exacerbations - average } \pm \text { SD }\end{array}$ & $1.34 \pm 0.62$ & $\begin{array}{l}1.23 \pm \\
0.68\end{array}$ & 0.6761 \\
\hline $\begin{array}{l}\text { Number of severe } \\
\text { exacerbations - average } \pm \text { SD }\end{array}$ & $0.39 \pm 0.60$ & $2.3 \pm 0.94$ & $<\mathbf{0 . 0 0 0 1}$ \\
\hline $\begin{array}{l}\text { Total number of } \\
\text { exacerbations - average } \pm \text { SD }\end{array}$ & $1.72 \pm 0.79$ & $\begin{array}{l}3.54 \pm \\
1.18\end{array}$ & $\mathbf{0 . 0 0 0 1}$ \\
\hline $\begin{array}{l}\text { General mortality rate }- \\
\text { percentage }(\%)\end{array}$ & $10.00 \%$ & $11.54 \%$ & 0.6452 \\
\hline $\begin{array}{l}\text { LTOT }=\text { long time oxygen therapy; NIV }=\text { non-invasive ventilation; SD }= \\
\text { standard deviation }\end{array}$ & \multicolumn{2}{|l}{} \\
\hline
\end{tabular}

We can easily observe the higher number of moderate exacerbations in the LTOT+NIV group, but this is counterbalanced by the increased number of severe exacerbations in the other group, resulting in significantly better evolution for patients with NIV.

A total of 4 deaths were registered, 1 from the LTOT + NIV group and 3 from the LTOT group which didn't indicate a statistically significant difference $(10 \%$ vs $11.54 \%(\mathrm{p}=0.6452)$.

\subsection{Economic results}

The total costs of the care in the follow-up period were divided into 2 categories:

-costs of the baseline care: price of the chronic medication + rent of the medical device (LTOT) / devices (LTOT + NIV);

-costs of the recurrences: costs of the care for moderate exacerbations $\mathrm{x}$ number of moderate recurrences adding the charges for hospital admission $\mathrm{x}$ number of severe exacerbations for each patient.

The average values for the above amounts for the 2 study groups are shown in the following table (Table 3 ).

Table 3. Average costs of care in the follow-up period for the 2 study groups

\begin{tabular}{|l|l|l|l|}
\hline Costs of medical care & $\begin{array}{l}\text { LTOT }+ \\
\text { NIV group } \\
(\mathbf{n}=10)\end{array}$ & $\begin{array}{l}\text { LTOT group } \\
(\mathbf{n}=\mathbf{2 6})\end{array}$ & $\begin{array}{l}\text { Statistical } \\
\text { significance } \\
(\mathbf{p})\end{array}$ \\
\hline Baseline care (euro) - & $3,833.2 \pm$ & $1,751.7 \pm$ & $<\mathbf{0 . 0 0 0 1}$ \\
average \pm SD & 687.3 & 359.9 & \\
\hline $\begin{array}{l}\text { Recurrences (euro) }- \\
\text { average } \pm \text { SD }\end{array}$ & $499.4 \pm$ & $2,976.8 \pm$ & $<\mathbf{0 . 0 0 0 1}$ \\
\hline Total (euro) - average \pm & 596,8 & $1,438.2$ & \\
SD & $4,332.6 \pm$ & $4,728.45 \pm$ & 0.4961 \\
\hline & 812.5 & $1,736.0$ & \\
\hline
\end{tabular}

The baseline costs were significantly greater for patients who benefit from domiciliary NIV, but the expenses with recurrences were meaningful lower, such that the total costs were approximately equal for the 2 groups (slightly greater for LTOT group).

QALY calculation was made adding the utility values for each month depending on the number of recurrences in the follow-up period for each patient. The average QALY and the corresponding ICER values are shown in the next table (Table 4).

Table 4. Cost-efficiency analysis for the study groups

\begin{tabular}{|l|l|l|l|}
\hline Cost-efficiency analysis & $\begin{array}{l}\text { LTOT + NIV } \\
\text { group }(\mathbf{n}=\mathbf{1 0})\end{array}$ & $\begin{array}{l}\text { LTOT group } \\
(\mathbf{n}=\mathbf{2 6})\end{array}$ & $\begin{array}{l}\text { Statistical } \\
\text { significan } \\
\text { ce }(\mathbf{p})\end{array}$ \\
\hline QALY - average \pm SD & $0.8012 \pm 0.17$ & $0.5295 \pm 0.11$ & $<\mathbf{0 . 0 0 0 1}$ \\
\hline ICER - average \pm SD & $5,641.71 \pm$ & $9,272.3 \pm$ & $\mathbf{0 . 0 0 5 4}$ \\
& $1,737.0$ & $3,681.9$ & \\
\hline
\end{tabular}

LTOT $=$ long time oxygen therapy; NIV = non-invasive ventilation; $\mathrm{SD}=$ standard deviation; QALY $=$ Quality Adjusted Life Years; ICER =

Incremental Cost-Effectiveness Ratio

The above data demonstrates the superiority of the LTOT + NIV treatment scheme over the LTOT in 4th GOLD stage COPD patients with a net gain of 3,630.6 EURO per QALY. Both quality adjusted life years and costefficiency ratio are more advantageous for patients with domiciliary NIV. 
A better visual representation of the differences is shown in the next plot graph with each case (Figure 1):

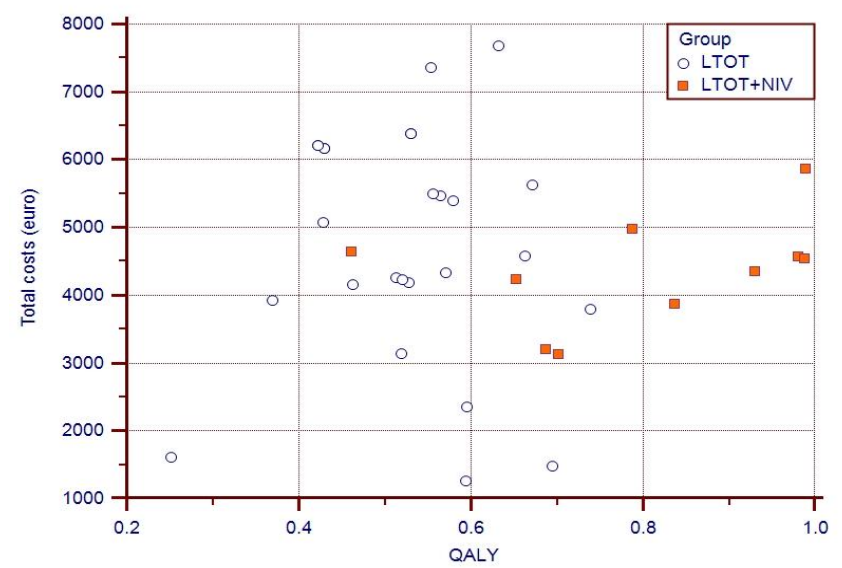

Fig. 1. Cost-efficiency plot graph for the study groups

\section{Discussion}

The current study demonstrates the superiority of the treatment scheme containing home-NIV for patients with Class risk D COPD after a severe, life-threatening exacerbation. The data shown presents significant differences to the RESCUE trial (29). That multicentre, randomized trial didn't show dissimilarity regarding the period to the next admission or mortality in the first 12 months after the introduction of NIV. Differences can be explained by inclusion criteria used (without clear diagnosis of Class Risk D ,COPD patients, only hypercapnia over $45 \mathrm{mmHg}$ at discharge), which can lead to inclusion of less severe cases (with reversible hypercapnia) and better prognosis.

Discussions related to the changes in life quality due to introduction of home- NIV are intense, starting from Australian trial of Non-invasive Ventilation in Chronic Airflow Limitation (30). Our study did not assess directly, with individual questionnaires, the quality of life in the groups, but uses estimated values from literature taking into account the months spent with the treatment of exacerbation. These variations would be lost in case of direct measurement which cannot be made every month. Thus, our results related to the evolution of life quality and implicit QALY, are relative, not evaluating directly the life quality changes determined by NIV itself.

The patient selection process indicates a low rate of enrolment (only $54.5 \%$ of initially identified patients were enrolled because of high loss rate in follow-up) which denotes the gravity of disease and also assures that we have selected a representative cohort who benefit most from domiciliary NIV.

Patients with COPD in this stage of the disease with chronic respiratory failure (with hypoxemia and hypercapnia) have reserved prognosis and limited pharmacological therapeutic options (the use of LAMA/LABA treatment consistent with the GOLD treatment recommendations, in patients with a high symptom load or LAMA/LABA/CSI, in exacerbating patients) (32).

Our improvement indicator in this study was the readmission rate for a severe exacerbation, without significant difference in general mortality rate. Even so, avoiding readmission has a beneficial effect on preserving pulmonary function and on health related quality of life.

Cost-efficiency assessment of home-NIV in different stages of COPD has been a debated topic in recent years, showing great differences between stable patients and those after a life-threatening recurrence. Analysing these articles, we can conclude that there is no considerable clinical or economic benefit for stable patients (17). However, patients recently discharged after a severe exacerbation represented a separate cohort to which most authors indicate a clinical improvement, without a correct assessment of health-related quality of life they concluded a higher cost-efficiency of NIV + LTOT vs LTOT alone $(12,15)$. The possibility of infection or the carrying of resistant multidrug strains is not negligible, which leads to high costs or poor prognosis for these patients (33).

Reporting the cost-efficiency index to the GDP per capita is a current practice in health management. In our case the net gain of ICER represents $31 \%$ from GDP per capita for every patient who was treated with domiciliary NIV over LTOT alone (GDP per capita for Romania in $2019=12482.9$ USD (31)). This is a considerable amount, and if the clinical evolution is also positive, this intervention worth considering in the selected group of patients. This approach may also be seen as a palliative measure in these advanced COPD patients, often with comorbidities ( as sleep apnea) where the prognosis and complex unmet needs are difficult to recognized and fulfilled $(34,35,36)$.

\subsection{Study limitations}

Some of the study characteristics can determine statistical bias or limitations to draw significant clinical or economic conclusions:

The reduced number of cases may not be representative for the whole cohort; increasing the study period or an eventual extension of study centres would increase the power of clinical and economic significance.

The costs of care in case of moderate and severe recurrences were approximated due to the great variability in duration of treatment, in-hospital days and other related expenses not covered by the insurance.

Assigning the utility values through approximation from previous studies can distort the real values resulted from assessment with individual questionnaires (EQ-5D-5L (28)), but also has the advantage to have distinct values for different stages of the disease over one single assessment in the case of individual questionnaires. 


\section{Conclusions}

Introduction of home-NIV for patients with COPD Class risk $\mathrm{D}$, is an expensive treatment option with multiple positive effects, but also some negative consequences (for example over life quality in general). Clinical and economic results should be interpreted taking into account the strong points and the limitations of the study.

The total number of recurrences showed a better result for the patients treated with home- NIV, especially on account of severe exacerbations with approximately the same general mortality. The baseline costs were significantly higher for the NIV group, but were compensated by the reduced charges for recurrence's treatment. The costs related to QALY showed even higher differences, reaching a net gain of approximately $31 \%$ of GDP per capita.

\section{Author contribution}

Conceptualization, E-B, K-B, L-G-D and Z-L-B.; methodology, K-B, L-G-D, C-M-D; software , L-G-D,CM-D.; validation, E-B, K-B, Z-L-B and L-D; formal analysis, L-G-D, C-M-D.; investigation, E-B, K-B, Z-LB; resources, Z-L-B,E-B.; data curation, L-G-D, E-B, KB.; writing - original draft preparation, E-B, Z-L-B.; writing - review and editing, Z-L-B, L-D.; visualization, L-D, K-B; supervision, E-B, Z-L-B, L-D, D-G; project administration, L-D, L-G-D, C-M-D.; funding acquisition, none. All authors have read and agreed to the published version of the manuscript.

\section{Funding}

This research received no external funding.

\section{Conflicts of Interest}

The authors declare no conflict of interest.

\section{References}

1. Vestbo J, Hurd S, Agusti A, Jones P, Vogelmeier C, Anzueto A, et al. Global strategy for the diagnosis, management, and prevention of chronic obstructive pulmonary disease: GOLD executive summary. Am J Respir Crit Care Med. 2013; 187(4):347-65, doi: 10.1164/rccm.201204-0596PP

2. Vogelmeier, C.F.; Criner, G.J.; Martinez, F.J.; Anzueto, A.; Barnes, P.J.; Bourbeau, J.; Celli, B.R.; Chen, R.;Decramer, M.; Fabbri, L.M.; et al. Global strategy for the diagnosis, management, and prevention of chronicobstructive lung disease 2017 report. GOLD executive summary. Am. J. Respir. Crit. Care Med.2017;195:557-582

3. Celli B, Cote C, Marin J, Casanova C, Montes de Oca M, Mendez R, et al. The body-mass index, airflow obstruction, dyspnea, and exercise capacity index in chronic obstructive pulmonary disease. N Engl J Med. 2004 Mar 4; 350(10):1005-12, doi:10.1056/NEJMoa021322

4. M Ilisie, L Davidescu, A Genda, R Ulmeanu- Fibrinogen and CRP biomarkers in patients with exacerbation of
COPD group C and D. European Respiratory Journal Sep 2014, 44 (Suppl 58) P3996; ISSN: 1399-3003

5. Rajnoveanu, R.-M.; Rajnoveanu, A.-G.; Ardelean, A.-B.; Todea, D.A.; Pop, C.-M.; Antoniu, S.A.; Motoc, N.S.; Chis, A.F.; Fildan, A.P.; Man, M.A. Pulmonologists Adherence to the Chronic Obstructive Pulmonary Disease GOLD Guidelines: A Goal to Improve. Medicina. 2020;56: 422

6. Lavinia Davidescu, R. Jurca, R. Ulmeanu, Value of adding behavioral-cognitive therapy to standard treatment in smoking cessation programe: results of Smoking Cessation Center Oradea on 7 years, ERJ September 1, 2014 vol. 44 no. Suppl 58 P4161

7. Ling S, Van Eeden S. Particulate matter air pollution exposure: role in the development and exacerbation of chronic obstructive pulmonary disease. Int $\mathrm{J}$ Chron Obstruct Pulmon Dis. 2009; 4:233-43, doi: 10.2147/copd.s5098

8. Seemungal T, Donaldson G, Paul E, Bestall J, Jeffries D, Wedzicha J. Effect of exacerbation on quality of life in patients with chronic obstructive pulmonary disease. Am J Respir Crit Care Med. 1998; 157(5 Pt 1):1418-22, doi: 10.1164/ajrccm.157.5.9709032

9. Aaron S, Donaldson G, Hurst G, Ramsay T, Wedzicha J. Time course and recovery of exacerbations in patients with chronic obstructive pulmonary disease. Am J Respir Crit Care Med. 2000; 161:1608-13

10. Struik F, Kerstjens H, Bladder G, Sprooten R, Zijnen M, Asin J, et al. The Severe Respiratory Insufficiency Questionnaire scored best in the assessment of healthrelated quality of life in chronic obstructive pulmonary disease. J Clin Epidemiol. 2013; 66(10):1166- 74, doi: 10.1016/j.jclinepi.2013.04.013

11. Murphy P, Rehal S, Arbane G, et al. Effect of home noninvasive ventilation with oxygen therapy vs oxygen therapy alone on hospital readmission or death after an acute COPD exacerbation: a randomized clinical trial. JAMA. 2017; 317(21):2177-2186, doi: 10.1001/jama.2017.4451

12. Dwarakanath A, O'Flynn H. Impact of domiciliary noninvasive ventilation (NIV) service in chronic ventilatory disorder on hospitalisation and quality-of-life: a Grimsby experience. Thorax 2009; Conference: British Thoracic Society, BTS Winter Meeting, London. 2009

13. Daina LG, Sabău M., Daina CM, Neamţu C, Buhaș CL, Bungau C, Aleya L, Bungau S, Tit DM, Improving performance of a pharmacy in a Romanian hospital through implementation of an internal management control system, Science of the Total Environment, 2019, 675:51-61, doi: 10.1016/j.scitotenv.2019.04.231

14. Ergan B, Oczkowski S, Rochwerg B, et al. European Respiratory Society Guideline on Long-term Home NonInvasive Ventilation for Management of Chronic Obstructive Pulmonary Disease. Eur Respir J2019; https://doi.org/10.1183/13993003.01003-2019

15. Sărmăşan, C, Drăghici, S, Daina, L. Identification, Communication and Management of Risks Relating to Drinking Water Pollution in Bihor County. Environmental Engineering and Management Journal, 2008, 7(6):769-774 
16. Chandra K, Blackhouse G, McCurdy B, Bornstein M, Campbell K, Costa V, et al. Cost-effectiveness of interventions for chronic obstructive pulmonary disease (COPD) using an Ontario policy model. Ont Health Technol Assess Ser. 2012; 12(12):1-61

17. Dretzke J, Blissett D, Dave CS, et al. The costeffectiveness of domiciliary non-invasive ventilation in patients with end-stage chronic obstructive pulmonary disease: a systematic review and economic evaluation. Health Technol Assess. 2015; 19(81):1-246, doi: 10.3310/hta19810

18. Jordan R, Majothi S, Heneghan N, Blissett D, Riley R, Sitch A, et al. Supported self-management for patients with moderate to severe chronic obstructive pulmonary disease (COPD): an evidence synthesis and economic analysis. Health Technol Assess 2015; 19(36):1-516. doi: 10.3310/hta19360

19. Dreher M, Storre J, Schmoor C, Windisch W. Highintensity versus low-intensity noninvasive ventilation in patients with stable hypercapnic COPD: a randomised crossover trial. Thorax. 2010; 65(4):303-8, doi: 10.1136/thx.2009.124263

20. Ram FS, Picot J, Lightowler J, Wedzicha JA. Noninvasive positive pressure ventilation for treatment of respiratory failure due to exacerbations of chronic obstructive pulmonary disease. Cochrane Database Syst Rev. 2004;(1):CD004104, doi 10.1002/14651858.CD004104.pub2.

21. Lavinia Davidescu,Ben Mansour Mohamed Azzedine,Milena Adina Man,Nicoleta Stefania Motoc,Ioan Anton Arghir,Ruxandra UlmeanuRelationship Between Obstructive Sleep Apnoea, Oxygen Desaturation and Cardiovascular Risk,Chemistry Magazine, Vol.70, 2019; 70 (10), 3582-3586;ISSN-L 1582-9049;

22. Richardson J, Iezzi A, Khan MA, Maxwell A. Validity and reliability of the Assessment of Quality of Life (AQoL)-8D multi-attribute utility instrument. The Patient. 2014; 7 (1): 85-96, doi: 10.1007/s40271-013-0036-x

23. Maxwell A, Özmen M, Iezzi A, Richardson J. Deriving population norms for the AQoL-6D and AQoL-8D multiattribute utility instruments from web-based data. Quality of Life Research. 2016; 25 (12): 3209-3219, doi: 10.1007/s11136-016-1337-z.

24. Daina LG, Neamtu C, Daina CM. Evaluating the analgesic consumption in a clinical emergency hospital. Farmacia. 2017; 65(3): 361-367

25. Sabau M, Bungau S, Buhas CL, Carp Gh, Daina LG, Judea-Pusta CT, Buhas BA, Jurca CM, Daina CM, Tit DM. Legal medicine implications in fibrinolytic therapy of acute ischemic stroke, BMC Medical Ethics. 2019; 20(1):70

26. Adab P, Fitzmaurice D. COPD in Primary Care: From Case Finding to Improving Patient Outcomes: NIHR Programme Grant 2011-16. (Unpublished.) Birmingham: Birmingham Lung Improvement Studies. 2014
27. Anexa la Ordinul privind aprobarea Normelor metodologice de aplicare in anul 2018 a Hotararii Guvernului nr. 140/2018 pentru aprobarea pachetelor de servicii si a Contractului-cadru - Anexa nr. 23A (Annex to the Order on the approval of the Methodological Norms for the application in 2018 of the Government Decision no. $140 / 2018$ for the approval of the service packages and of the Framework Contract - Annex no. 23A)

28. https://euroqol.org/eq-5d-instruments/eq-5d-51about/(accessed at 17.06.2020)

29. Struik FM, Sprooten RT, Kerstjens HA, Bladder G, Zijnen $M$, Asin J, et al. Nocturnal non-invasive ventilation in COPD patients with prolonged hypercapnia after ventilatory support for acute respiratory failure: a randomised, controlled, parallel-group study. Thorax. 2014; 69(9):826-34, doi: 10.1136/thoraxjnl-2014-205126

30. McEvoy RD, Pierce RJ, Hillman D, et al. Nocturnal noninvasive nasal ventilation in stable hypercapnic COPD: a randomised controlled trial. Thorax. 2009; 64(7):561-566

31. https:/www.imf.org/external/pubs/ft/weo/2019/02/weoda ta/weorept.aspx?pr. $=53 \&$ pr.y $=6 \&$ sy $=2017 \&$ ey $=2021 \& \mathrm{~s}$ $\mathrm{csm}=1 \& \mathrm{ssd}=1 \&$ sort $=$ country $\& \mathrm{ds}=. \& \mathrm{br}=1 \& \mathrm{c}=968 \& \mathrm{~s}=\mathrm{NG}$ DPD \%2CPPPGDP\%2CNGDPDPC \%2CPPPPC \%2CPCPI PCH \&grp $=0 \& \mathrm{a}=($ accessed at 10.02 .2020$)$

32. Valipour A, Tamm M, Kociánová J, Bayer V, Sanzharovskaya M, Medvedchikov A, HaaksmaHerczegh M, Mucsi J, Fridlender Z, Toma C, Belevskiy A, Matula B, Šorli J. Improvement In Self-Reported Physical Functioning With Tiotropium/Olodaterol In Central And Eastern European COPD Patients. Int J Chron Obstruct Pulmon Dis. 2019 Oct 11;14:2343-2354.

33. Zaha DC, Kiss R, Hegedüs C, Gesztelyi R, Bombicz M, Muresan M, Pallag A, Zrinyi M, Pall D, Vesa CM, Micle $\mathrm{O}$, Recent Advances in Investigation, Prevention, and Management of Healthcare-Associated Infections (HAIs): Resistant Multidrug Strain Colonization and Its Risk Factors in an Intensive Care Unit of a University Hospital, BioMed Research International, Volume 2019, Article ID 2510875, https://doi.org/10.1155/2019

34. Rajnoveanu RM, Rajnoveanu AG, Fildan AP, Todea DA, Man MA, Motoc NS, Mosoiu D. Palliative Care Initiation in Chronic Obstructive Pulmonary Disease: PrognosisBased, Symptoms-Based or Needs-Based?. International Journal of Chronic Obstructive Pulmonary Disease. 2020;15:1591.

35. Creagh-Brown BC, Shee C. Palliative and end-of-life care for patients with severe COPD. European Respiratory Journal. 2009 Feb 1;33(2):445-6.

36. Budin, Corina E.; Ciumarnean, Lorena; Maierean, Anca; Rajnovean, Ruxandra; Gergely, Bianca D.; Man, Milena; Aluas, Maria; Cozma, Angela; and Bordea, Roxana I. "Therapeutic alternatives with CPAP in obstructive sleep apnea," Journal of Mind and Medical Sciences.2019; Vol. 6 : Iss. 2 , Article 